\title{
Sustainable Water Management: Implications for Mining in Environmentally Sensitive Areas
}

\author{
Harmony K. Musiyarira ${ }^{1 *}$, Ditend Tesh ${ }^{1}$ and Godfrey Dzinomwa ${ }^{2}$ \\ ${ }^{1}$ Department of Mineral and Process Engineering, Namibia University of Science and Technology, Windhoek, Namibia \\ ${ }^{2}$ Paasol Resources (Pvt), Ltd, Harare, Zimbabwe
}

\begin{abstract}
Namibia is known as water stressed country with a limited amount of fresh water. Therefore, the use of water is an important topic in the country's development agenda. Water is a shared and finite resource, with high social, cultural, environmental and economic value. However, freshwater resources are under pressure from ore processing, industrialization, urbanization and the demands of a growing population. In Namibia, ore processing, coupled with the anticipated increase in water demand for human consumption and other uses, has created significant stress on the limited water resources of the country. This is critical in the mining industry as water remains typically the prime environmental medium (besides air) that is affected by mining activities. This study sought to investigate the strides made in water management in mining, especially in environmentally sensitive areas of Namibia. Most mining companies operate next or alongside farms, national parks and fishing areas. The overall objective of this research was to highlight the current practices in Namibia's mineral industry operating in environmentally sensitive areas especially in areas where uranium is being mined and processed. The methodology consisted of comprehensive literature review, field visits to the case study areas, and comparative studies with best practices. This study shows that over a ten-year period, freshwater consumption was reduced by over 55\% per tonne of milled ore in uranium mines, resulting in substantive financial savings as well as the delay in water augmentation through desalination. The strategies employed by the Namibian companies involve inclusive stakeholders' engagement, recycling and reuse, and the minimization of water losses. The realization that the water challenge cannot be solved by any one party acting alone has been fundamental in ensuring environmental compliance within the mining industry in Namibia. Namibia's industrial leaders have increasingly recognized that reducing the water footprint of mining activities must be one of the key performance indicators for management. The major finding of this study was that Namibia with its unique ecosystems, mineral reserves, and emerging industries can harness a wide range of resources both to improve the welfare of its citizens and to protect the integrity of its environment.
\end{abstract}

Keywords: cleaner production, environmentally sensitive, freshwater, stakeholder engagement, water stewardship

\section{Introduction}

In Namibia, ore processing coupled with anticipated increases in water demand for human consumption and other uses, has created significant stress on the limited water resources of the country. Freshwater resources are under pressure from ore processing, industrialization, urbanization and the demands of a growing population. This is critical in the mining industry as water remains typically the prime environmental medium (besides air) that is affected by the mining activities. This study sought to investigate the strides made in water management in mining in some environmentally sensitive areas of Namibia. Most of the mining companies operate next or alongside farms, national parks and fishing areas. Therefore the future of mining depends on the sustainability of the earth's water resources, which are increasingly under pressure. Water supply and quality have emerged as the top risks facing the minerals industry. The overall objective of this research was to highlight the current practices in Namibia's mineral industry, which is operating in environmentally sensitive areas, especially in areas where uranium is being mined and processed. Namibia is one of the countries that could face an especially significant increase in water stress by 2040 (Maddocks et al 2015). This means that businesses, farms, and communities in these countries in particular may be more vulnerable to water scarcity than they are today.

\section{Overview of Mining in Namibia}

Namibia is a primary source for gem-quality diamonds mined inland and offshore and it is the fourth-largest producer of uranium in the world. Namibia produces gem quality rough diamonds, uranium oxide, special high-grade zinc and acid-grade fluorspar, as well as gold bullion, blister copper, lead concentrate, salt and dimension stone. Rio Tinto and Vedanta produce and export uranium oxide and special high-grade zinc respectively. Paladin Energy's Langer Heinrich Uranium mine achieved nameplate production in 2013. Whilst De Beers works with the Government of the Republic of Namibia (GRN) through

* Corresponding Author: H.K. Musiyarira, hmusiyarira@nust.na, phone: +264 61-2072076

Copyright @ 2017 Canamaple Academia Services, http://press.camdemia.ca

DOI: 10.15273/gree.2017.02.024 
Namdeb Holdings in a 50:50 joint venture, producing some of the world's finest gem diamonds. Namibia's output increasingly comes from the marine environment, reflecting the technical expertise of Debmarine Namibia. Further value addition is boosted by eleven cutting and polishing factories, supplied with rough diamonds from Namibia Diamond Trading Company (NDTC), worth approximately US $\$ 300$ million annually (Ralston et al 2015).

\subsection{Mining and the environment in Namibia}

Worldwide, the mining industry has always posed a great threat to protected areas. While the environmental consequences may be the most obvious, the indirect social effects may also impact on protected area values (Phillips 2001). The uranium mines are located in the Erongo region and they are all in a national park. The potential for significant impacts is greater when mining occurs in remote and environmentally or socially sensitive areas.

Namibia is one of the few countries that incorporated environmental sustainability in her constitution. Article 95 emphasizes the importance of environmental protection by stating that Namibia shall actively promote and maintain the welfare of her people by adopting policies aimed at the maintenance of ecosystems, essential ecological processes and biological diversity of Namibia and the utilization of living natural resources on a sustainable basis for the benefits of all Namibians. It is known that minerals are essential to every sector of the nation's economy and will play a determining role in the feasibility of the emerging technologies that sustainability will require. Water is increasingly recognized as a critical issue for sustainable development. Although the mining industry's overall 'water footprint' is relatively small compared to other sectors, most mining companies have recognized the importance of fresh water and the need to take actions to reduce the mining industry's water consumption.

\section{Water}

Corporate water management is a complex, iterative process that requires companies to assess their water situation, evaluate the impacts of their activities on water, and determine the best course of action on a continual basis (Dragasakis et al 2013, WBCSD 2012). Water risks are different from the water impacts for a company, since one company's risks can depend as much on what happens outside their fence line as what happens within it. In this respect, it is crucial that businesses, communities, and other stakeholder groups work together to manage the water resources effectively (WBCSD 2012). The ICMM (2014) report on catchment management strategies reveals that historically mining has approached water as an operation issue, one that is managed inside a fence with a focus on water efficiencies and control of effluent discharges. The same report highlights that its members have come to recognize that even the most water efficient operations that stringently manage water discharges can still be subject to significant water risks manifesting from outside the operation fence line at the catchment level. Water stewardship is an emerging concept within the industry which supports sustainable and equitable production and use of water in mining operations. This broader concept involves the care and management of water through its life cycle.

\subsection{Freshwater challenges}

Namibia is a water stressed country with a limited amount of fresh water. Therefore the use of water is an important topic in the country's development agenda. Freshwater is a precious shared resource with significant social, environmental and economic value. Most of the mining activities are mainly found in water stressed areas and are increasingly in competition with different users, presenting challenges to the security of supply. The future of mining companies and society depends on the availability of freshwater resources, which are increasingly under pressure. Globally, the per capita availability of freshwater is steadily decreasing and the trend will inevitably continue as the world's population grows towards 9 billion. Many regions of the world are reaching a point of "freshwater stress", where freshwater resources can no longer support the demands of human populations (WBCSD 2012). The approach to water management cannot remain business as usual but it will need a paradigm shift in the implementation of the best practices which will minimize the potential for adverse environmental, social and economic impacts.

\subsection{Best practices in water management}

The rate of water reuse and recycling in ore processing is often very high at mine sites, especially in areas with arid climates (Rankin 2011). A number of innovative water conservation practices are being developed and implemented to reduce water use. The recognition and adoption of best practice principles are considered fundamental cornerstones of sustainable development for the uranium industry. Best practices are the development of operation specific methodologies that integrate global and local knowledge, which enables planning to produce the best available and most practicable methods to address an operation's site specific requirements and conditions. Best practices, by nature, are not static but continuously evolving in response to new technology, increased understanding and awareness of environmental and social impacts, and increasing regulatory requirements and public expectations.

\subsection{Mining practices}

Over the years, the mining industry has generated a considerable amount of guidance on how mining practices must evolve for the sector to responsibly fulfil its role in society's transition to sustainability (Brantes and Olivares 2008). However these practices are not widely embraced, and the degree to which they are implemented varies across political jurisdictions, subsectors of the industry and even with private or public and state owned enterprises. Kogel et al (2014) argue that a large number of mining companies are increasingly recognizing that reducing their water footprint must be a high management priority. The mining industry recognizes that sustainability issues comprise part of a new 
business reality, in which traditional responses no longer fully satisfy the expectations of investors, communities, employees and other stakeholders. However, while the new business reality is clear to most, the appropriate business response can be elusive and sustainability implementation can be challenging (Ramage 2014).

In reality, sustainable development involves managing resources in a way that is conducive to long term wealth creation and the maintenance of capital (natural, human, social, economic and physical). The International Council on Mining and Metals' (ICMM) definition of sustainable development for the mining and metals sector means that investments should be technically appropriate, environmentally sound, financially profitable and socially responsible. This perspective extends naturally to mineral resources, which are themselves a form of endowed natural capital, and they are an important source of wealth creation (Shields et al 2012).

\subsection{Environmental regulations in Namibia}

The Ministry of Environment and Tourism (MET) was established in 1990 and it is responsible for safeguarding Namibia's environmental resources. Since then, the MET has implemented far-reaching policy and legislative reforms in the environmental sphere in an attempt to alleviate many of the constraints that the environment places upon people and vice versa. Namibia's Policy for Prospecting and Mining in protected Areas and National Monuments aims to promote sustainable development in Namibia by allowing prospecting and mining in protected areas with strict environmental management. The policy stipulates that any mining developments in a National Park must be balanced against the risk that it could negatively interfere with the potential for long-term sustainable development. The policy states that a full Environmental Assessment (EA) is required for any mining in a Protected Area and/or National Monument, as set out in the Environmental Management Act (2007). The mission of the MET is to maintain and rehabilitate essential ecological processes and life support systems, to conserve biological diversity, and to ensure that the utilization of natural resources is sustainable for the benefit of all Namibians, both present and future, as well as the international community, as provided for in the Constitution.

\subsection{Water quality regulations in Namibia}

The Water Resources Management Act No. 11 of 2013 was enacted in order to provide for the management, protection, development, use and conservation of water resources; to provide for the regulation and monitoring of water resources and to provide for incidental matters. The Environmental Management Act is in line with modern legislative trends, including; adherence to the polluter pays principle, the inherent need to incorporate adequate provisions to achieve 'reduction-at-source' in the areas of pollution control and waste management and the need to consider alternatives and to avoid or minimize negative impacts wherever possible. Before a mine can commence with its activities it must obtain a Record of Decision and a Letter of Authorization.
However, the Letter of Authorization from the MET is not a blanket permission to implement the project. The applicant is still required to obtain a sectoral license or permit, depending on the nature of the envisaged project. Individual mines are responsible for managing their wastewater and industrial effluents as well as for applying for exemption permits, if required.

The Water Act, 1956 (Act 54 of 1956) is the principal legal document according to which the Department of Water Affairs currently operates. The relevant Sections of the Water Act are 21-24, 26 and 170. Section 21 promotes water conservation. It stipulates that water which has been used for industrial purposes shall, after purification, be returned at the nearest convenient point to the place from which the water was abstracted and shall not be diminished in quantity more than is justified by its use.

The Minerals (Prospecting and Mining) Act, 1992 (Act 33 of 1992) stipulates that it shall be a term and condition of any mineral license that the holder of such mineral license shall: prepare in such form as may be determined by the Commissioner for the approval of the Commissioner: an environmental impact assessment indicating the extent of any pollution of the environment before any prospecting operations or mining operations are carried out and an estimate of any pollution, if any, likely to be caused by such prospecting operations or mining operations. If any pollution is likely to be caused, an environment management plan indicating the proposed steps to be taken in order to minimize or prevent to the satisfaction of the Commissioner any pollution of the environment in consequence of any prospecting operations or mining operations carried out by virtue of such mineral license (MME 1992). The above clause is important in preventing the pollution of water resources by mining industry.

\subsection{Monitoring and control}

The use of water in mining has the potential to affect the quality of surrounding surface water and groundwater. In response to environmental concerns and government regulations, the mining industry worldwide increasingly monitors the water discharged from mine sites, and it has implemented a number of management strategies to prevent water pollution. Water issues and management vary from site to site and they must be addressed locally, but in general, the mining industry seeks to minimize its impact on water quality and availability. Section 17 of Part V of the EMA empowers the Environmental Commissioner to conduct inspections to monitor compliance with the Act and with conditions stipulated in the Environmental Clearance Certificate. If monitoring and/or inspections reveal that a developer is not abiding by the conditions of the Environmental Clearance Certificate or has contravened the EMA, the Environmental Commissioner has the power to suspend or cancel the Certificate for a period s/he may determine. The certificate can be reinstated once the environmental Commissioner is satisfied that the person concerned has rectified the failure that led to the suspension. 


\section{Methodology}

The methodology used in this study consisted of a comprehensive literature review, field visits to the case study areas and interviews. Statistical surveys and comparative studies with mining companies outside Namibia were an integral part of this study. Reports and documents from various stakeholders were analyzed. Most of the detailed information from the mining companies could not be incorporated in this paper, because it was regarded as confidential information. However, trends were drawn from the information.

\section{Results}

Over the last few years, the mines have applied a number of different water management strategies which are aimed at reducing their freshwater intake, reducing the volumes of effluent discharged to the environment, minimizing the deterioration in water quality in the mine circuits and treating the water to the required level for reuse or discharge. Namibia's industrial leaders have increasingly recognized that reducing the water footprint of mining activities must be one of the key performance indicators for management. The realization that the water challenge cannot be solved by any one party acting alone has been fundamental in ensuring environmental compliance within the mining industry in Namibia.

\subsection{Enforcement of legislation}

The ultimate way of ensuring the sustainability of mining in sensitive areas is through developing and strengthening legislation and sound policies coupled with enforcement mechanisms and putting proportionate pressures on the industry to instill good corporate citizenship principles in all their operations. In as much as there has been such enforcement, there are still capacity challenges for the enforcement agencies, which is further complicated by having overlapping roles and responsibilities in administering environmental related acts which are administered under different line ministries. The best way for ensuring that mining in sensitive areas is done without damaging the environment to a greater extent is to ensure that standards and protocols for pollution prevention and monitoring are strictly enforced.

\subsection{Water stewardship initiatives}

Namibia has water supply challenges and therefore water management will remain a critical issue. Uranium mining companies in Namibia have been developing a vision together on water stewardship, which includes a broader concept of catchment water management as opposed to the individualistic water management approaches of the past. Public meetings, interviews and consultations always reveal community concerns related to mining activities.

The Uranium industry through the Namibia Uranium Association (NUA) has been spearheading a campaign to encourage the mines to work together in developing water stewardship initiatives in an inclusive and transparent manner that ensures sustainable water management. This initiative has the potential to decrease the competition for water between mining operations and human consumption. The all-inclusive stakeholder engagement strategy employed by the mines was seen as a good leading practice which other countries seeking to strike a balance between competing interests including mineral extraction, environmental and wildlife conservation and farming, may emulate.

\subsection{Freshwater consumption}

This study shows that over the past two decades freshwater consumption has generally decreased by close to $55 \%$ per tonne of uranium oxide $\left(\mathrm{U}_{3} \mathrm{O}_{8}\right)$ produced. This reduction in freshwater consumption came through water management and sustainability principles. Rössing Uranium's target for freshwater consumption is $0.8 \mathrm{~m}^{3}$ per tonne of $\mathrm{U}_{3} \mathrm{O}_{8}$ based on their stakeholder report (RUL 2015) as shown in Figure 1. The water management plan was mainly influenced by the parent company's performance standards and guidelines. The aim of the plan is to ensure sufficient, safe and sustainable use and protection of water resources and ecosystems. It is also important to note that lower tonnages at fixed water usages, combined with lower grades, result in a higher consumption of fresh water per tonne of $\mathrm{U}_{3} \mathrm{O}_{8}$ produced.

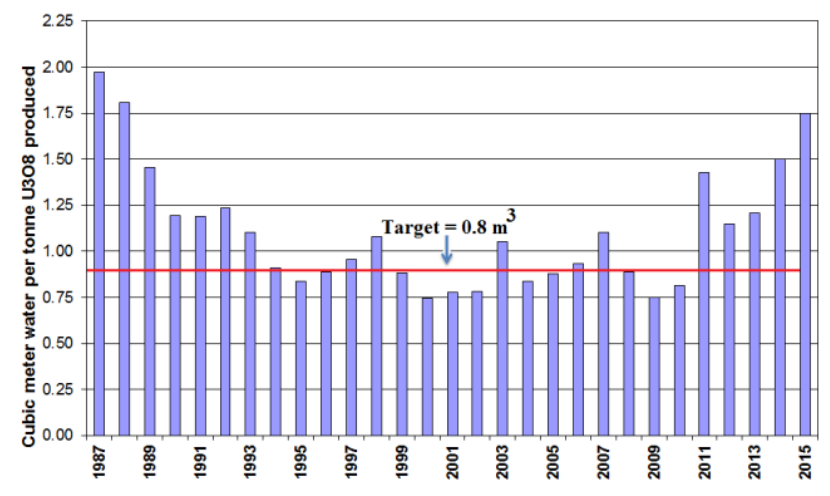

Figure 1. Average freshwater consumption per tonne of $\mathrm{U}_{3} \mathrm{O}_{8}$ produced.

\subsubsection{Freshwater consumption / tonne of milled ore}

This study shows that over the past three decades freshwater consumption was reduced from an average high of $0.65 \mathrm{~m}^{3}$ to an average low of $0.27 \mathrm{~m}^{3}$ per tonne of uranium ore milled. This freshwater reduction resulted in substantial financial savings as well as delaying water augmentation through desalination. The drop in 2010/ 2011 as shown in Figure 2 was as a result of unusual excessive rainfall experienced in Namibia and most of the mines harvested that water and used it in their operations, which in itself was commendable as a sustainability measure. The active mines are recycling approximately $50-60 \%$ of their process water. Water segregation is playing a crucial role in the water management strategies advocated by the mines and this has led to decreased freshwater consumption per tonne of milled ore, as shown in Figure 2. 


\subsection{Water supply}

The past twelve years have seen an increase in the population, building activities, the establishment of numerous industries and new uranium mines as shown in Figure 3 and the increase in water demand from 2007. All this resulted in a steep

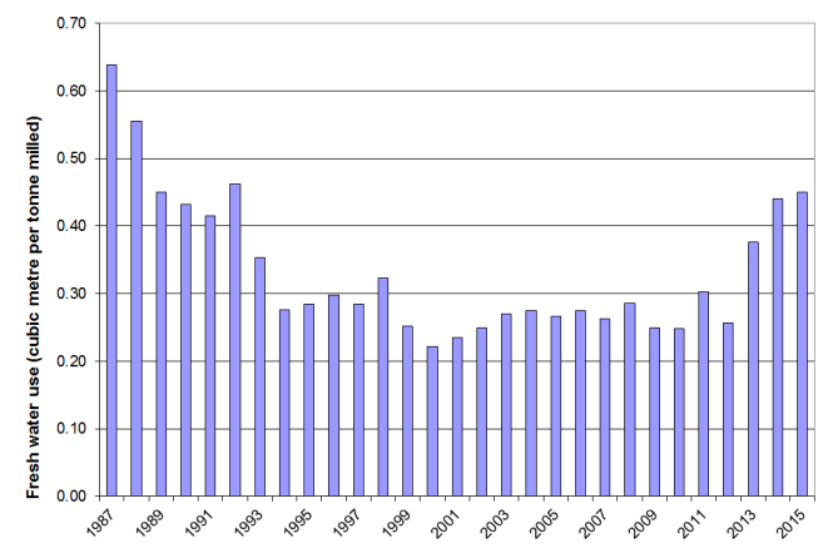

Figure 2. Average freshwater consumption per tonne milled.

growth of water demand to the extent that it almost exceeded the available resources. This led Areva Namibia Uranium Company to build its own desalination plant with a capacity of 20 million cubic meters per annum. It is difficult to predict when demand will outstrip supply as over the medium term it depends to a large extent on how much water can be obtained and conveyed from the additional construction of new desalination plants and also on how the mining and other industries' demand will develop and also work to reduce their water footprint.

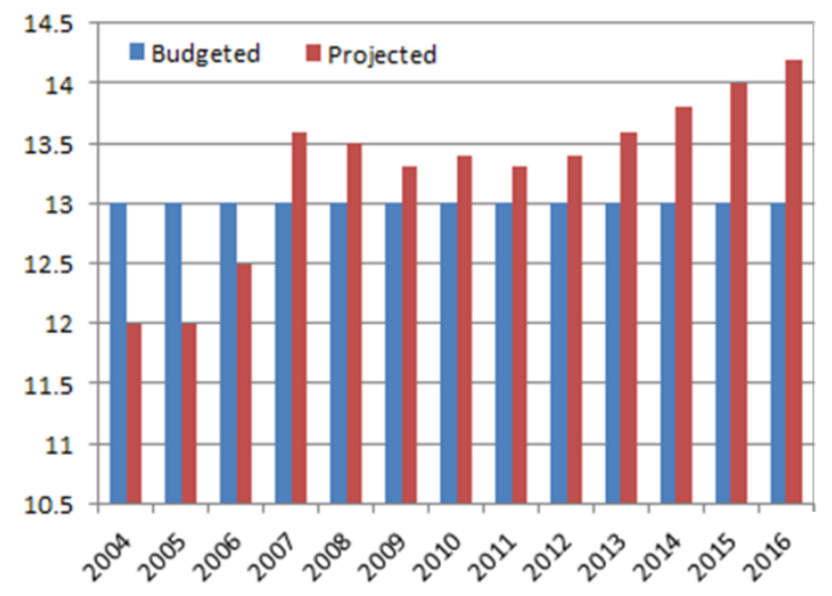

Figure 3. Erongo region water demand.

Water has to be managed in a holistic way across its life cycle. Managing water resources and eliminating waste at source is a cleaner production philosophy. This philosophy when drilled into mine workers will bring in the required changes to how freshwater is managed at the mine. Efficient freshwater use starts with minimizing the input and losses associated with it. Basic good housekeeping aspects of replacing worn out hoses, sealing leaks and using pressurized water for cleaning equipment coupled with the use of recycled water for dust suppression have the potential to save at least $3000 \mathrm{~m}^{3} /$ day of fresh water.

\subsection{Research and development}

Literature studies reveal that the most worrying fact is that during the past decades, the global mining industry has dedicated only small expenditures to research and development, compared to the $15 \%$ to $40 \%$ levels in other industries. The same applies in the context of Namibia where, with the prevailing low commodity prices, most companies have embarked on cost cutting measures including activities related to strategic research for the organizations. Mining companies in Namibia need to undertake water-saving actions and initiatives and together set targets and develop a vision on water stewardship which must include a broader concept of catchment water management.

\section{Conclusions}

Namibia is a water stressed country with a limited amount of freshwater. Freshwater resources are under pressure from ore processing, industrialization, urbanization and the demands of a growing population. In Namibia, ore processing, coupled with anticipated increase in water demand for human consumption and other uses, has created significant stress on the limited water resources of the country. This study sought to investigate the strides made in water management when mining in environmentally sensitive areas of Namibia. This study revealed that over a 30-year period, freshwater consumption was reduced by over $55 \%$ per tonne of milled ore in uranium mines resulting in substantial financial savings as well as the delay in water augmentation through desalination. The strategies employed by the Namibian uranium industry involve inclusive stakeholders' engagement and joint water stewardship approaches, recycling and reuse as well as the minimization of losses. The realization that the water challenge cannot be solved by any one party acting alone has been fundamental in ensuring environmental compliance within the uranium industry in Namibia. Namibia's industrial leaders have thus increasingly recognized that reducing the water footprint of mining activities must be one of the key performance indicators for management.

\section{References}

Brantes, R. and G. Olivares, 2008. Best practices and efficient use of water in the mining industry. COCHILCO (Chilean Copper Commission). http://www.cochilco.cl/descargas/english/research/resea rch/best_practices_and_the_efficient_use_of_water.pdf.

Dragasakis, K., J. Mastoris, E. Mastoris, A. Shilegarska and M. Pophristova, 2013. Water resources management, risk assessment, and mitigation. Proceedings of the 6th International Conference on Sustainable Development in the Minerals Industry, Milos Island, Greece. 
ICMM (International Council on Mining and Metals), 2014. A Practical Guide to Catchment Based Water Management Strategies for the Mining and Metals Industry, London.

Kogel, J.E., N. Trivedi and M.A. Herpfer, 2014. Measuring sustainable development in industrial minerals mining. International Journal of Mining and Mineral Engineering, 5(1): 4 - 18.

Maddocks, A., R. S. Young and P. Reig, 2015. Ranking the world's most water - stressed countries in 2040. World Resources Institute.

MME (Ministry of Mines and Energy), 1992. Minerals Act of Namibia. Windhoek / Namibia.

Phillips, A., 2001. Mining and protected areas. MMSD Working Paper No. 62.

Ralston, J., H. Musiyarira, D. Tesh, V.D. Cabo and S. Donegan, 2015. Mineral processing in Namibia: scientific, engineering and environmental challenges.
Bridging the technology divide through collaboration, Proceedings of the 1st Africa Australia Technical Mining Conference 2015, 99 - 102.

Ramage, A.C., 2014. A roadmap for implementing sustainability in mining enterprises. International Journal of Mining and Mineral Engineering, 5(1): 75 88.

Rankin, W.J., 2011. Minerals, metals and sustainability: meeting future material needs. CSIRO publishing.

Rössing Uranium Limited (RUL), 2015. Report to stakeholders 2015.

Shields, D.J., S.V. Solar and W.H. Langer, 2012. Sustainable development and industrial minerals. Industry and Environment (Special Issue), 133 - 142.

WBCSD, 2012. Water for business, initiatives guiding sustainable water management in the private sector. http://www.bcsd.org.tw/sites/default/files/node/domain _tool/678.file.2161.pdf. Accessed on March 10, 2017. 